\title{
Longitudinal Analysis of Foreign Direct Investment in Ghana
}

\author{
Daudi Yeboah ${ }^{1 *}$, Martin Nyaaba Adokiya ${ }^{1}$, and Philip Kojo \\ Ochire $^{2}$ \\ ${ }^{1}$ Department of Epidemiology, Biostatistics and Disease Control, \\ School of Public Health, University for Development Studies, \\ Tamale, Ghana \\ ${ }^{2}$ Department of Physician Assistantship, Narh-Bita College, Tema, \\ Ghana \\ ${ }^{*}$ E-mail of the corresponding author:dyeboah@uds.edu.gh
}

August 25, 2021

\section{Abstract}

Foreign direct investment (FDI) is a factor that drives the growth and development of an economy. The inflow of FDI spans across the various sectors of the economy. The study seeks to identify the trend of FDI in the country and also determine whether the number of projects and the sectors they are coming from significantly affect FDI inflow. The study used secondary data mainly collected from the Ghana Investment Promotion Centre (GIPC). The data is made up of FDI realized in the country, number of projects that led to the realization of FDI, and the sectors of the economy from 1994 to 2017. Trend and Longitudinal Data analysis were the methods employed to analyze the data in R 3.4.3. The study identified that the inflow of FDI into the country is generally increasing over the years, although there are some fluctuations in the flow. FDI from all sectors was very low from the beginning of the study (1994), raised a little at the 4th year (1997) especially the Service sector, and declined through to the 12th year (2005). There was an enormous upswing from 2005 through to the end of the study period (2017). This growth of FDI follows an exponential trend with the manufacturing sector given off the highest FDI inflow in Ghana followed by Building and Construction sector. It was also established that sectors and the number of projects undertaken have a statistically significant effect (F-statistic 24.8067 and p-value 2.22e-16) on FDI in Fixed Effect Model. As a result, the country's investment drives policies should be all-inclusive across all sectors to effectively achieve higher inflows of FDI to Ghana. Currently, it is cheaper to invest in certain regions due to the lower cost of labor, and of which investors 
could exploit to their advantage and thereby increasing FDI inflows.

\section{Keywords: Foreign Direct Investment; sector; project; Ghana}

\section{Introduction}

Mostly, developing countries are faced with economic hardships as there are not enough national savings to fund investment activities. Developing countries in such situations initially acquired loans from international commercial banks and resulting in debt crises. Many of these countries are indirectly compelled to reform their investment guidelines to attract more stable forms of foreign capital. Through globalization, FDI has been realized as a vital stimulus for productivity and economic growth for both developing and developed countries. Receipt of foreign capital augments economic growth and subsequently tends to develop justifiable conditions to attract investment inflows into their economies. FDI is considered as one of the best means to acquire foreign capital at the expense of being in debt. Both developed and developing countries believe that FDI can assist them through their stagnation in economic development and even avoid the poverty trap[1].

FDI is a factor that drives the growth and development of an economy[2]. FDI has been seen as a smart substitute to loans from banks as a basis of inflows of capital to the country[3]. FDI is considered among the most illustrious global capital flows of a nation. It indicated that FDI involves the acquisition of more than 10 percent shares of a foreign-based firm and implies a long-term interest in effective managerial control over the firm in a different country[4].

Ghana among other developing countries is challenged with the problem of a resource gap annually due to low-income levels and domestic savings, escalation of expenditure of government, increased tendency to consume imports and inadequate foreign exchange resources. Subsequently, majority of the needed resources for growth and development would be from foreign countries; official sources[4], FDI (portfolio investments, bond, and bank lending) [5].

The government of Ghana, as a result of the GIPC Act, guarantees and protections have been given to foreign firms to be able to transfer through authorized banks funds for loan repayment, net profits, or dividends attributable to investment in the country[6]. The earnings from interest related to investing in the country, liquidation, or sale of the business are also guarded by the Act. Ghana relatively attracts a small amount of FDI inflows from the time of the inauguration of a more permissible investment framework earlier in the 1960s[7]. Regardless of the diminished role of FDI, the policies of the government remain unchanged from the promotion of foreign investment, specifically in certain prioritized sectors of the Ghanaian economy[7].

Ghana actively engages in the global competition for FDI across its sectors of the economy[8]. That is helping the economy to emerge from agricultural dependence to a modern, dynamic, and technologically advanced economy with higher per capita incomes and greater equity. The contribution to FDI from 
the various sectors of the economy has not gained much attention and could be the result of the relatively low inflows of FDI into the country since the induction of an additional accommodating investment framework. Using nationally representative data, the study presents a comprehensive review of the extent of these inflows as well as the sectorial distribution needed to gauge the real effect of FDI on the economy.

\section{Methods}

\subsection{Data Source}

We obtained data from the GIPC. The data is made up of FDI realized in the country, the number of projects that led to the realization of the FDI, and the sectors of the economy from 1994 to 2017. FDI is classified as a dependent variable while the independent variables are the sectors of the economy and the number of projects.

\subsection{Method of Analysis}

We adopted both descriptive and inferential statistics. The descriptive analysis was performed to obtain the preliminary information of the study sample. We employed two inferential statistics methods to analyze the data collected; trend and longitudinal data analysis.

\subsection{Trend Analysis}

We used the trend analysis to give the clearest signal of the long-run movement in the series of FDI realized in the country.

\subsubsection{The Linear Trend Analysis}

This implies a straight line of long-run growth or decline. The linear trend is of the form;

$$
Y(t)=\beta_{0}+\beta_{1} t
$$

where $\beta_{0}$ and $\beta_{1}$ are trend parameters

\subsubsection{The Quadratic Trend Analysis}

The quadratic trend is of the form;

$$
Y(t)=\beta_{0}+\beta_{1} t+\beta_{2} t^{2}
$$


where $\beta_{0}, \beta_{1}$, and $\beta_{2}$ are trend parameters

\subsubsection{The exponential Trend Analysis}

The exponential growth trend is of the form;

$$
Y(t)=\beta_{0} \beta_{1} e^{t}
$$

where $\beta_{0}$ and $\beta_{1}$ are trend parameters

\subsubsection{Measures of Accuracy}

Mean Absolute Percentage Error (MAPE)

It measures the accuracy of fitted time series values and it expresses the accuracy as a percentage.

$$
M A P E=\frac{\sum_{t=1}^{n}\left|\left(Y_{t}-\hat{Y}_{t}\right) / Y_{t}\right|}{n} \times 100
$$

where $Y_{t}=$ Actual value $\hat{Y}_{t}=$ Forecast value $\mathrm{n}=$ Number of Forecast

Mean Absolute Deviation (MAD)

It measures the accuracy of the fitted time series values in the same unit as the data which helps conceptualize the amount of error.

$$
M A D=\frac{\sum_{t=1}^{n}\left|\left(Y_{t}-\hat{Y}_{t}\right)\right|}{n}
$$

where $Y_{t}=$ Actual value $\hat{Y}_{t}=$ Forecast value $\mathrm{n}=$ Number of Forecast

Mean Squared Deviation (MSD)

The MSD is equivalent to Mean Square Error (MSE) which measures the accuracy of the fitted time series values. Outliers in observations have a greater effect on MSD than on MAD.

$$
M S D=\frac{\sum_{t=1}^{n}\left|\left(Y_{t}-\hat{Y}_{t}\right)\right|^{2}}{n}
$$

where $Y_{t}=$ Actual value $\hat{Y}_{t}=$ Forecast value $\mathrm{n}=$ Number of Forecast

\subsection{Longitudinal Data Analysis}

We employed longitudinal data analysis because FDI from the various sectors of the economy was observed and measured continually over a period of time. This will help us to examine the relationship between and within individual sectors 
of the economy by investigating their observations and measurements over the study period. The individual unit of the study is the sectors of the economy that are measured continuously over time (from 1994 to 2017).

\subsubsection{Fixed effects models}

Fixed effects indicate the covariate effects that are fixed across a number of projects and sectors of the economy. In this model, the effect of time-invariant is assumed for FDI that might be correlated with the number of projects and sectors of the economy. Also in a fixed effects model, the unobserved variables are allowed to have any associations whatsoever with the observed variables. Fixed effects models control for, or partial out, the effects of time-invariant variables with time-invariant effects. Each sector has its characteristics that probably might impact or bias FDI and that there is a need to control for this. The model can be represented as:

$$
Y_{i_{j}}=\alpha+\beta X_{i_{j}}+\epsilon_{i_{j}}
$$

\subsubsection{Random effects models}

Random effects signify the covariate effects that vary among subjects under study. The effects are subject-specific (randomly unobservable) since each subject is a random entity drawn from a population. The entity-specific random variable does not correlate with the independent variables and the individual differences are shown by error term[9]. It also presents an alternate method of estimation that adopts constants to be random parameters. The study ensures that the individual sector's error terms are not correlated to allows a time-invariant variable to play the role of an explanatory variable. The model can be represented as:

$$
Y_{i_{j}}=\alpha+\beta X_{i_{j}}+U_{i}+\epsilon_{i_{j}}
$$

where

$U_{i}$ is the random component determinant of the $i^{\text {th }}$ unit.

\subsubsection{Hausman Test}

Hausman test is used in the selection of the best model by comparing the estimators of the models tested. It is usually tested with the null hypothesis that one of the compared models indicates consistent and efficient results but the other model is consistent but inefficient. Thus, it compares estimates of the 
fixed effect model and random effect model in longitudinal data analysis. The selection of the best model depends on the information gathered about each specific component and the endogeneity of explanatory variables.

$H_{0}$ : Individual effects are not correlated with error terms in the model.

$H_{1}$ : one model is inconsistent.

\section{Results}

\subsection{Profile plot of Sectorial Distribution of the National FDI}

Figure 1 below presents the sectoral distribution of FDI in the country. FDI flow in Ghana is mainly categorized under 8 sectors. The sectors include agriculture, tourism, building/construction, export trade, general trading, liaison, manufacturing, and service. The figure below shows that the FDI flow in the country from these sectors is generally increasing over the study period. The variability of the FDI values among the various sectors is smaller at the beginning of the study period compared to the end of the study.

Again, the sectors that recorded the highest FDI at the beginning of the study period tend to maintain their status throughout the end of the study period. FDI from all sectors was very low from the beginning of the study (1994), raised a little at the 4th year (1997) especially the Service sector, and declined through to the 12th year (2005). There was an enormous upswing from 2005 through to the end of the study period (2017). The least FDI in 1994 and 2017 was from tourism whilst the FDI from other sectors kept fluctuating over the period under study. The highest FDI within the study period was in the year 2011 and from the building/construction sector.

\subsection{The number of projects undertaken by each sector}

Figure 2 presented below indicates that in 1994 (the first year) the sectors received a very low number of projects, increased in the second and third years (1995 and 1996), and remained steadily to the end of the study period. The

variability in the number of projects among the various sectors is almost the 


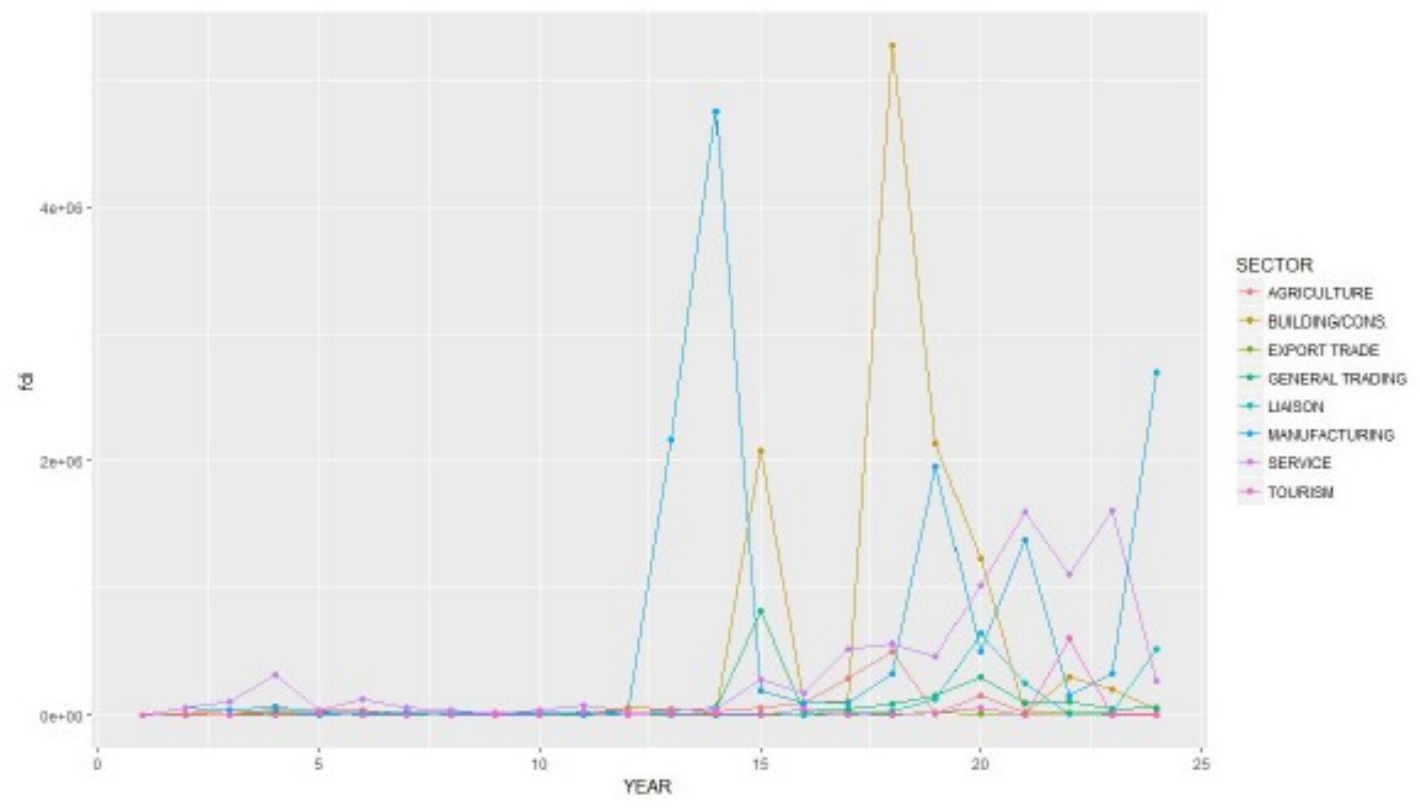

Figure 1: The Profile plot of Sectorial Distribution of the National FDI

same throughout the years under study. The highest number of projects was undertaken by the service sector in the year 2011 .

Again, the sectors that had the highest number of projects at the beginning year (1994) remained the highest at the end of the period (2017). The least number of projects was seen in the tourism sector and the highest number of projects undertaken within the period under study was by the service sector.

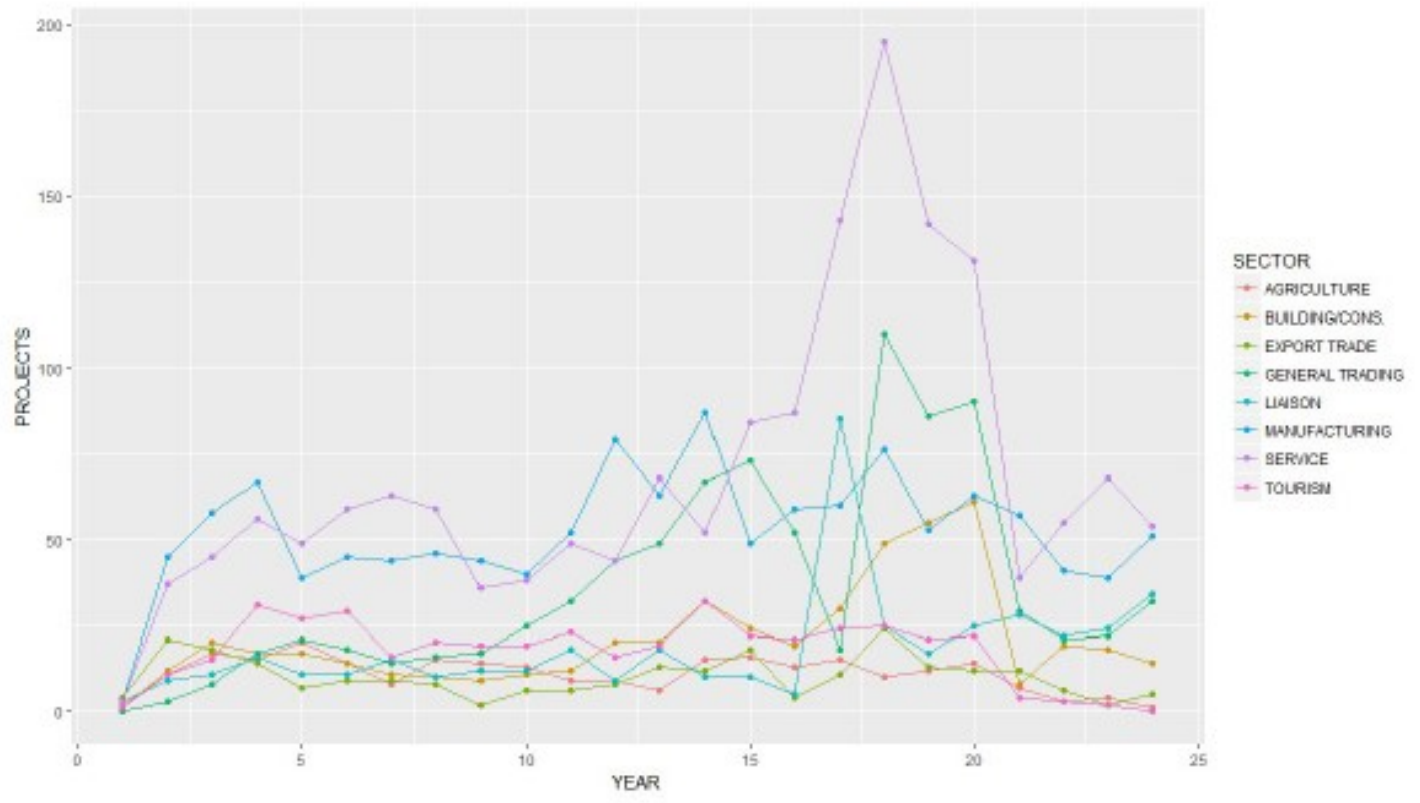

Figure 2: Number of projects undertaken by each sector 


\subsection{Trend Analysis}

The world's economy, through globalization, has increased in Market competition and the suitability of such drift brings about an investigation of Foreign Direct Investment that can drive the development of Ghana. As indicated in figure 3 below FDI in the country is generally increasing from year to year. However, the FDI inflow was almost constant from 1994 to 2005 and increased to 2007. FDI inflow in the country declined from 2011 to 2017 .

Trend analysis was performed to determine the long-run effects of FDI in the country. This consists of a linear, quadratic and, exponential growth model.

The growth of FDI in Ghana over the years follows an exponential trend. With the attitudes and government policies towards FDI, the growth trend in Ghana's FDI does not differ from the rest of the world. The world's FDI is seen to have grown exponentially over time. Thus, FDI $(Y t)$ increases as an exponential function of time $(t)$. The selection of trend of the study was based on accuracy measures (MAPE, MAD, or MSD) measuring the average errors between the actual and the fitted values have smaller values for exponential trend compared to the linear and quadratic trend.

The exponential growth model is

$$
Y_{t}=37253184\left(1.24067 e^{t}\right)
$$

Where $Y_{t}$ is the FDI value realized, $t$ is time in years.

Table 1: Measures of Accuracy

\begin{tabular}{llll}
\hline Model & MAPE & MAD & MSD \\
\hline Linear & $8.617 \mathrm{E}+02$ & $1.0867 \mathrm{E}+09$ & $1.9962 \mathrm{E}+18$ \\
Exponential & $1.3501 \mathrm{E}+02$ & $1.1724 \mathrm{E}+09$ & $3.4574 \mathrm{E}+18$ \\
Quadratic & $8.9305 \mathrm{E}+02$ & $1.0885 \mathrm{E}+09$ & $1.9960 \mathrm{E}+18$ \\
\hline
\end{tabular}

\subsection{Determining whether there is a significant difference in the number of projects and the sector it is coming from on FDI}

Ghana has become a viable investment climate but investors channel their investment in specific areas. According to the data collected, FDI flow in Ghana is mainly categorized under 8 sectors. Among these sectors are service, export trade, agriculture, general trading, liaison, building/construction manufacturing, and tourism. The results of the study showed that the variability of the FDI values among the various sectors is smaller at the beginning of the study period 


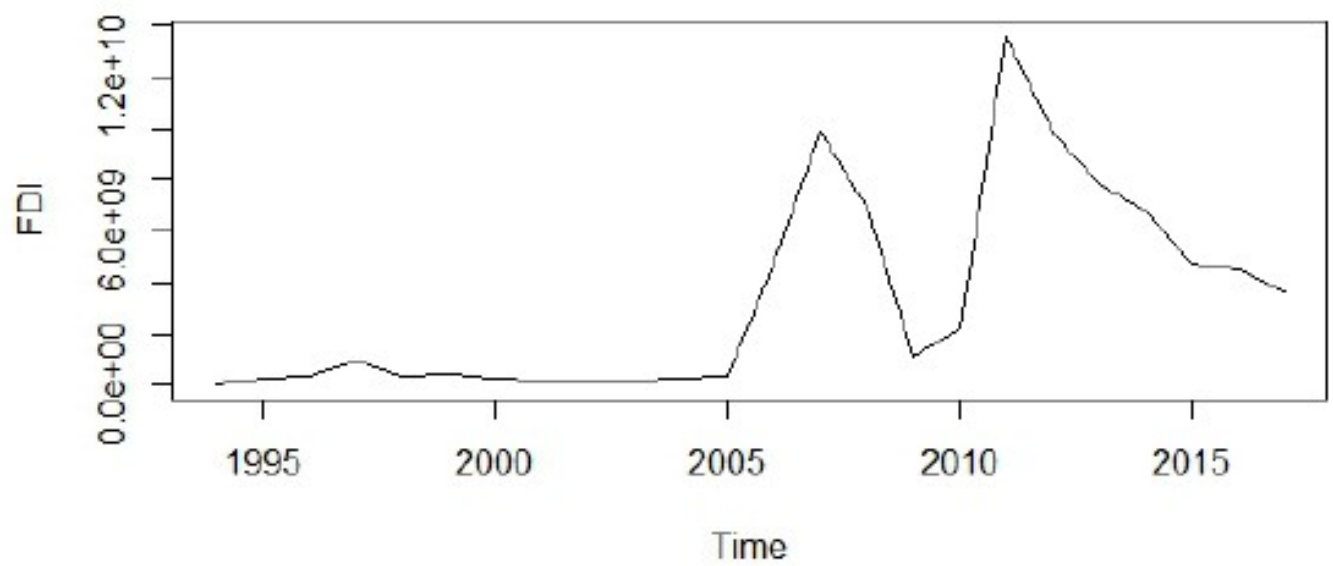

Figure 3: Plot of FDI

(1994) compared to the end of the study period (2017). This indicates that the FDI flows in the country from these sectors are generally increasing over the year (that is from the beginning to the end of the study period). Nevertheless, FDI inflows differ from sector to sector.

\section{Fixed effect model}

Given making a comparison between the FDI realized in the country (Dependent Variable) and the sector it is coming from as well as the number of projects undertaken by each sector (Independent variables), the study (Tables 2 and 3) indicated that generally sectors and the number of projects contributes significantly to the realization of FDI in the country ( $\mathrm{p}$-value $=2.22 \mathrm{e}-16$ is less than the significance level of 0.05). The variation in FDI accounted for by sector and number of projects is between $48.8 \%$ and $57.8 \%$. However, the building/construction, export trade, manufacturing, service, and tourism sectors were found to be significant but general trading and liaison were also insignificant to FDI in the country.

The model for the fixed effect is

$\log F D I=0.0160 X_{1}+0.7601 X_{2}-1.9928 X_{3}+1.1262 X_{4}+1.0101 X_{5}-1.2289 X_{6}$

Where

$X_{1}=$ No. of projects

$X_{2}=$ Building $/$ cons

$X_{3}=$ Export trade

$X_{4}=$ Manufacturing

$X_{5}=$ Service 
$X_{6}=$ Tourism

The model indicates that with the sectors held constant, $\log$ FDI would be increased by $1.605 \%$ of the number of projects undertaken. The estimates of the model indicate that building/construction sector is $76.01 \%$ better than agriculture, export trade is $199.28 \%$ less than agriculture, manufacturing is $112.62 \%$ better than agriculture, service $101.01 \%$ better than agriculture and tourism are $122.89 \%$ less good than agriculture. In view of this, the study identified the manufacturing sector as the sector that attracts the highest proportion of FDI in the country.

Table 2: Coefficients of Fixed effect model

\begin{tabular}{lllll}
\hline & Estimates & Std. Error & t-value & $\operatorname{pr}(>|\mathrm{t}|)$ \\
\hline No. of projects & 0.0160494 & 0.0057458 & 2.7933 & 0.005923 \\
Building/cons. & 0.7601183 & 0.3761045 & 2.0210 & 0.045117 \\
Export trade & -1.9927806 & 0.3717175 & -5.3610 & $3.19 \mathrm{e}-07$ \\
General trading & 0.0610190 & 0.4036604 & 0.1512 & 0.880056 \\
Liaison & -0.9479027 & 0.4828157 & -1.9633 & 0.051527 \\
Manufacturing & 1.1261927 & 0.4417301 & 2.5495 & 0.011827 \\
Service & 1.0100767 & 0.4993709 & 2.0227 & 0.044943 \\
Tourism & -1.2288680 & 0.3785662 & -3.2461 & 0.001453 \\
\hline
\end{tabular}

Table 3: Measures of Fixed effect model fit

R-Squared 0.57782

Adj. R-Squared 0.48756

F-statistic $\quad 24.8067$

p-value $\quad 2.22 \mathrm{e}-16$

Random effects model

The effect of sector and number of projects undertaken on FDI are highly significant. The random effect model showed an F-statistic of 39.9643 with p-value $=$ $5.2224 \mathrm{e}-15$ less than $\alpha$-value $=0.05$. The model explained between $30.9 \%$ and $31.7 \%$ of the variation in FDI accounted for by sector and number of projects. The model indicates that the sector has a negative influence and number of projects on $\log$ FDI. The random effect model is as shown below;

$$
\log F D I=16.1047871-0.1297454 \text { Sectors }+0.0465320 \text { No. of Projects }
$$


Table 4: Coefficients of Random effect model

\begin{tabular}{lllll}
\hline & Estimates & Std. Error & t-value & $\operatorname{pr}(>|\mathrm{t}|)$ \\
\hline Intercept & 16.1047871 & 0.2986145 & 53.9317 & $<2 \mathrm{e}-16$ \\
SECTOR & -0.1297454 & 0.0558327 & -2.3238 & 0.02129 \\
NO. OF PROJECTS & 0.0465320 & 0.0047706 & 9.7539 & $<2 \mathrm{e}-16$ \\
\hline
\end{tabular}

Table 5: Measures of Random effect model fit

R-Squared 0.31725

Adj. R-Squared 0.30941

F-statistic $\quad 39.9643$

p-value $\quad 5.2224 \mathrm{e}-15$

\section{Hausman test}

The efficacy of FDI can well be assessed if the magnitude to which it has been able to create the necessary linkages within the economy is well established. This linkage, however, depends on the various sectors of the economy and the number of projects undertaken within each sector.

The Hausman test (table 6) below is used to compare the fixed effect model and random effect model and informs which estimation technique to use. The Hausman test indicated a rejection of the null hypothesis since the $\mathrm{p}$-value $=$ 0.04101 is less than $\alpha$-value $=0.05$ and that one model is inconsistent. Since one of the models of inconsistent, it implies the fixed effect model is the best model for the study.

\begin{tabular}{ll} 
Table 6: Hausman test \\
\hline Chi-Square & 45.782 \\
Df & 2 \\
p-value & $1.144 \mathrm{e}-10$ \\
\hline
\end{tabular}

\section{Discussion}

The economy of Ghana has increasingly advanced in market competitiveness through globalization, and hence the suitability of such drift brings about an investigation of FDI that can drive its development. The study identified that the inflow of FDI into the country is increasing over the years, although there are some fluctuations in the flow. The growth of FDI in Ghana over the years follows an exponential trend. With the attitudes and government policies towards FDI, the growth trend in Ghana's FDI does not differ from the rest of the world[10]. 
Investors consider a number of the sectors, before investing in the host countries due to modern technological advancement. Ghana has become a viable investment climate but investors channel their investment in specific areas. According to the data collected, FDI flow in Ghana is mainly categorized under 8 sectors. Among these sectors are agriculture, building/construction, export trade, general trading, liaison, manufacturing, service, and tourism. The results of the study showed that the variability of the FDI values among the various sectors is smaller at the beginning of the study period (1994) compared to the end of the study period (2017). This indicates that the FDI flows in the country from these sectors are generally increasing over the year (that is from the beginning to the end of the study period). FDI flows into Ghana keep on depressed up until the reforms of the 1990s. It raised sharply during the last decade before declining in the advent of the global financial crisis and rising again in its aftermath. Being thoughtful of the firm's capabilities and the ability to attract foreign firm participation in investment projects is important in terms of attracting the right type of FDI inflows into Ghana[11].

Nevertheless, FDI inflows differ from sector to sector. It was seen from the results that manufacturing is the sector that gives the highest FDI inflow in Ghana followed by the building and construction sector. The Service sector was third, fourth was general trading, fifth was liaison whereas the agriculture sector was the sixth sector in FDI inflows in the country. Also, the tourism sector was seventh and the eighth sector in FDI in Ghana was export trade. This means that the Ghanaian economy is very weak in exporting goods and services to other parts of the world. The manufacturing sector holds the highest number of firms in the country (especially in the Greater Accra Region) and also indicates almost twice the number of firms in the services sector[11].

Again, we identified from the study that generally sectors and the number of projects contribute significantly to the realization of FDI in the country. Building/construction, export trade, manufacturing, service, and tourism sectors were found to be significant to FDI in the country. It is evident from the study that certain sectors of the economy are more developed than others and as a result reflected in the level of FDI realized. The country needs to extend its investment policy framework evenly to all other sectors to increase FDI inflows into the country. FDI inflows to the country could substantially contribute to achieving Millennium Development Goals (MDGs)[12]. The fixed effect model is found to be the best model for the study that examines the contribution of various sectors of the economy and the number of projects undertaken to FDI inflow in Ghana. It indicates that over $50 \%$ of FDI inflows depend on the sectors of the economy. FDI inflows to Sub-Saharan Africa has a fixed effect model[13].

\section{Strengths and limitations}

This study used nationally representative data and robust statistical techniques to generate estimates that are generalizable to the entire Ghanaian economy. Despite the importance of the study's findings for decision-makers and stake- 
holders, we acknowledge that there are limitations to these findings especially when it comes to the impact of FDI on the economic growth of Ghana. We, therefore, recommend a further study to be conducted to ascertain the real effect of FDI on the economic growth and development of Ghana.

\section{Conclusions}

The conceptualization of the direction of FDI from simple trend and the longitudinal analysis outlined in the study is an indication of the growth prospects of the Ghanaian economy. We identified from the study that generally sectors and the number of projects contribute significantly to the realization of FDI in the country. This study has provided evidence that Ghana manufactures lots of products in the country but the rate at which we export them to other parts of the world is very low. As a reslt, FDI as a strategic module of investment is requied by the country to sustain its economic growth and development through creation of jobs, expansion of existing manufacturing industries, enhancing its export rates and the engagement in short and long-term projects in the field of education, healthcare, and research and development.

\section{References}

[1] Lee J.-W.; Son H.H.; Zhuang J. Brooks, D.H.;Hasan R. Closing development gaps: challenges and policy options. Manila Asian Development Bank (ADB) Economics Working Paper Series 209, 2010.

[2] Wang, M. \& Wong, M. C. S. Foreign direct investment and economic growth: The growth accounting perspective. Economic Inquiry, 47:701710, 2009.

[3] Asteriou D. \& Papathoma K. Agiomirgianakis, G. The Determinants of Foreign Direct Investment: A Panel Data Study for the OECD Countries. OECD, 2003.

[4] World Bank. World development indicators. Technical report, Washington D. C.: World Bank, 2010.

[5] IMF. Country report, report no. 13/187. Technical report, IMF, 2013.

[6] Owusu-Frimpong N. Mmieh, F. and Mordi, C. Evaluating the contribution of the export sector to real gdp growth rate under structural adjustment programme (sap): The case of ghana. Thunderbird International Business Review, Vol. 54, No. 4:pp. 493-507, 2012.

[7] Frimpong, J. and Oteng-Abayie E. Bivariate causality analysis between fdi inflows and economic growth in ghana. In MPRA Paper No. 351, 2006.

[8] Ferry, A. Foreign Direct Investment and Corruption. Colorado State University, 2012. 
[9] Green, W. Econometric analysis. New York University, Fifth Edition, 2001.

[10] Jones, G. The Evolution of International Business. London, U.K.: Routledge, 1996.

[11] Emmanuel A. \& Marie S. The presence of foreign firms in Ghana: The Role of Physical, Financial and Governance Infrastructure. F-33208-GHA$1,2016$.

[12] UNCTAD. United nations conference on trade and development. In Foreign direct investment, 2008.

[13] Gichamo, T. Z. Determinants of Foreign Direct Investment Inflows to SubSaharan Africa: a panel data analysis. Sdertrns University-Department of Economics, 2012. 